\title{
Localism and the Community Shop
}

\author{
Eric Calderwood and Keri Davies \\ Institute for Retail Studies, University of Stirling
}

A finalised version of this paper was published in Local Economy (2013), 28(3), 339-349 


\title{
Localism and the Community Shop
}

\author{
Eric Calderwood and Keri Davies \\ Institute for Retail Studies, University of Stirling
}

Corresponding Author:

Dr Keri Davies

Institute for Retail Studies

University of Stirling

Stirling FK9 4LA

United Kingdom

Tel: $\quad$ (+44) 1786467408

email: $\quad$ b.k.davies@stir.ac.uk

Dr Keri Davies is a Senior Lecturer in the Institute for Retail Studies, Stirling Management School, University of Stirling

\begin{abstract}
There has been considerable interest in recent years in the establishment of community retail enterprises; local shops owned and run by the local community often as an alternative to the closure of the last privately-owned shop in the area. Government efforts to give local communities more rights and powers, including a community right to bid for 'assets of community value, ' would seem to offer new opportunities for such enterprises. However, there are more barriers to the establishment and continued running of these enterprises than might appear at first sight. Community retail enterprises often need specific support from local and national organisations tailored to the different stages in their development if they are to fulfil their potential.
\end{abstract}

Keywords: Retailing, Co-operatives, Social Enterprises, Localism 


\section{Localism and the Community Shop}

\section{Introduction}

This paper is concerned with the relationship between the concept of localism and the growing number of community shops and community retail enterprises. Localism can mean many things; in recent years it has been applied in particular to the idea that as much political power as possible should be devolved down to the lowest possible level, the local community. Freed from burdensome regulation or control, each community can make decisions that reflect local priorities or initiate developments that will fill gaps in the provision of economic or social activities.

Community retail enterprises would seem to fit naturally into such a local framework. The number of community-owned shops in the United Kingdom has seen significant growth in recent years (Perry and Alcock, 2010; Calderwood and Davies 2012). They represent a local response to a persistent lack of or a withdrawal of retail provision within the community. Their establishment draws upon local financial capital but also social capital in the form of management expertise and volunteers to run the shop.

The paper draws a distinction between the trading element of the enterprise - the community shop - and the entity established to create and run that shop, which we term the 'community retail enterprise' (CRE). The latter is included because it is the CRE that mobilises community involvement, provides local control of the shop and decides on the direction of its trading policies.

\section{Localism and Community Retail Enterprises}

The aim of the 'localism agenda,' as expressed in the Localism Bill 2011, which applies primarily to England, is to drive decisions about matters that affect local communities to the 
lowest possible level of decision-making (DCLG, 2011). Hall (2011, p.2584) describes it as a tripartite proposal: "for the decentralisation of power (but not resources) away from centralised authority; for participatory decision making through local authorities and neighbourhood groups; and for alternative modes of service delivery outside of the state." The proposals should permit communities to get involved in small developments and to establish social enterprises that can provide local services. This may make it easier to retain certain forms of community activity in under-served rural and urban areas.

It reflects the notion of localism as a 'bottom-up' phenomenon in which the freedom to act allows the community autonomy to develop its own priorities and standards. Pratchett (2004) argues that there is a difference between local democracy (as embodied in locally elected bodies) and local autonomy which can be considered in three separate ways: as freedom from central interference; as freedom to effect particular outcomes; and as the reflection of local identity, which is presumed to flow, in part, from the first two elements.

But, as Pratchett notes, there is the problem of what exactly the locality is seeking to be autonomous from and therefore how it can effect outcomes in reality (pp. 366-67). This is a particular issue for a CRE.

The primary reason for forming almost all CRE is to create a new shop or to take over a failing one (Calderwood and Davies, 2012); it reflects a decline in the number of small stores that is now seen to be affecting even prosperous and otherwise successful villages close to urban areas (DEFRA, 2006). Fulton and Hammond Ketilson (1992) described this situation as having many of the elements of a Prisoners' Dilemma. Individuals in a community decide to shop at a more distant large store because it is beneficial for them to do so. However, when a large number of people decide to do this, the result may be that the local shop closes down; in attempting to increase their individual welfare, the members of a community may actually reduce the overall welfare of the community. On the other hand, the establishment 
of a CRE leads to collective ownership of a business, and so the members may be more likely to see the effect on others of their actions when they bypass their local shop or business (Grott, 1987).

Schoenborn (2011) argued that community run, consumer cooperative retail models may be able to overcome the market disadvantages faced by small retailers by increasing local loyalty (Thomas and Cornforth, 1989) and leveraging other forms of in-kind support. This approach was supported by McEntee (2010) who saw the desire amongst the food co-ops set up in the U.S.A. to support local farmers and to be environmentally sustainable as an expression of localism (Cotterill, 1982; Cox, 1994). In a similar vein, many of the CREs established in the UK in recent years have aimed to sell locally produced foods (Calderwood and Davies, 2012).

On the other hand, Hall (2011) queried whether localism can have any real impact in the face of the global restructuring of the retail sector which is bringing about many of these changes. Despite their relative isolation, CREs still operate in markets populated primarily by capitalist firms and some argue that they may survive only in a marginal way by the practice of self-exploitation i.e. by accepting lower wages or poor working conditions (Welford, 1990). Whereas even twenty years ago local residents had to make a choice to travel to other more distant shops, the development of internet shopping and supermarket home delivery services means that even quite distant retailers now provide fierce local competition. And many of the developments in retail supply chains do not suit small local shops which require small order quantities and are normally not computerised.

So, whilst a CRE should reflect local identity through its links to the community it is less clear whether it can either have or want complete freedom from 'interference' if it is to succeed in its goals. We will now turn to a survey of CREs which examined their 
development and some of the ways in which their form and purpose may change over time. This, in turn, will highlight the volume and nature of the support that many of the CRE have received in order to remain in operation.

\section{Methodology and data collection}

The study draws on data collected from a sample of CRE to examine the reasons for their establishment and the links that they have established in the economic and social spheres. Our sampling frame was a group of 197 active CRE trading in Great Britain in early 2009. This list of was compiled using publicly available material from the Plunkett Foundation in England and Wales, the Co-operative Retailing Network (CRN) in Scotland and DEFRA.

Given the varied nature of the sector, a two-pronged approach was used for the survey work. First, all of the identified CRE, were sent a questionnaire covering a range of organisational features within the CRE and operational issues involving the shop. Some 93 usable questionnaires were returned, a $47 \%$ response rate which was considered to be a robust sample. Most of the responses came from England (79), with 11 from Scotland and 3 from Wales; these figures were roughly in line with the respective CRE populations at that time. In addition, in the summer of 2009 , twenty-one community shops were visited to provide additional insight and depth of answer. During all of these visits discussions took place with shop managers, shop assistants or volunteers, and, in some cases, with committee members. A more detailed look at some of the data collected in the survey can be found in Calderwood and Davies (2012).

Finally, in mid-2012 telephone interviews were conducted with staff of the Plunkett Foundation and the Co-operative Retail Network in order to update some of the qualitative information relating to the sector and to discuss the current operations of these bodies. 


\section{Main Findings}

The analysis of the information provided by the CREs in 2009 suggested that many of them had moved from being marginal enterprises to more established business models, whilst retaining their social purpose. We visualise this movement as a form of U-shaped curve denoting cost/ organisation trade-offs (Figure 1). This trade-off is shown as moving through stages from a privately-run shop to a CRE (and possibly back to a privately-run shop) and the subsequent analysis and discussion of the survey results utilises this curve. Just as importantly it is suggested that each phase also raises specific issues about localism and the role of outside support in the establishment of a CRE and the subsequent running of a community shop.

[Insert Figure 1 about here]

\section{i. $\quad$ Pre-purchase phase}

At point A in Figure 1, the shop is assumed to be privately-run with sufficient profit to satisfy the needs and desires of the shop owner. If profitability were to fall then it would eventually reach a point (shown here by the 'break-even' line) where it ceases to be viable as a privately-run business and its losses have to be met by external resources (B). Some shops may cease trading or switch to other lines of business as soon as this point is reached but numerous studies (Smith and Sparks, 2000) have shown that some will continue trading either in the hope that they can be turned around or because the owners have no other options. There is no available data that will allow us to establish exactly how many local shops have fallen into this position in recent years but it is clear that significant numbers have done so and many of these shops have now closed. 
Often, communities are unaware that their local shop is under threat until it is too late. The work of DEFRA (2006) can be seen as one way of approaching the issue as it attempted to identify in a broad manner the likely future extent of shop closures in a range of local communities in England. This work has been taken forward by the Plunkett Foundation which (where possible) uses the information available to it to alert local communities to the fragile nature of a local shop or the possibility of a shop purchase.

\section{ii. Pre-opening phase}

It is at this point ( $\mathrm{C}$ in Figure 1$)$ that local action is needed to get a community shop established. Some CRE have been set up with no apparent input from external bodies, mainly where they already have sufficient funds to open, possibly donations from local sources. But the evidence from the Plunkett Foundation and from our survey suggests that many of these have not been set up on a sustainable basis and they have a much higher closure rate than other CREs. Sometimes the problem is a lack of understanding of how to operate the shop leading to a poor supply chain, including buying goods from another local shop rather than from wholesalers, poor pricing or problems in managing staffing. But they are also unlikely to have established a strong structure to help to support the CRE over a longer period, relying instead on an individual or a small group of residents.

Where groups decide that they might need assistance, the Plunkett Foundation reported that they receive around 12 enquiries each month about establishing CRE, yet the level of new starts peaked at over 40 in 2009 and fell back to around half that number in 2010 and 2011. Part of the problem may be the difficulty of acquiring suitable assets, as noted in the Localism Act but it is also likely that the responses to those enquiries make it clear to the groups just how much effort will be required to establish and run a CRE. 
In our survey many of the CRE noted the role of informal networks and contacts in helping the community to raise funds or to gain access to a range of different forms of expertise. For example, in successful CREs the management committee or board were both well-connected already and probably well-versed in the means by which to seek out further information or to co-opt others to the cause. They were able to furnish the CRE with a range of different skills from within the community itself, including legal and accounting advice through to the installation of plumbing. And yet many also belonged to networks which enabled them to tap into funding from a range of public and private sources and thus provided the CRE with a stronger base from which to grow.

But, unlike the self-starters, these CRE also commented on the help and advice provided by the Plunkett Foundation, along with the work of the Rural Community Councils in England and the CRN in Scotland. The Plunkett Foundation in particular has moved away from providing CRE with purely retail advisors and towards community advisors. These are often former community shop managers whose experience has given them an ability to understand and address underlying organisational and governance issues as well as trading problems. Once the members of the CRE understand what they want their shop to represent, then more specific advice can be provided in the relevant operational areas. It is an approach that helps to tailor the community shop to its locality and provides it with an ethos that is not focused on profitability alone but on what the community really wants from its shop.

At this point the CRE may also be able to gain financial aid from external bodies in relation to the set-up and operation of the community shop. The Plunkett Foundation estimate that around $95 \%$ of the community shops which open have received some form of support from an outside agency. In our survey, 39 (41\%) CREs in the survey had received funding and 53 $(60 \%)$ had received some form of training assistance, consultancy or other advice from an external body or agency in the previous year alone. Support was most evident in the newer 
fledgling enterprises with a variety of bodies providing grants to get the business up and running. A third of the successful grants were used to acquire an existing business, to refurbish premises or other initial costs. Awards for this type of investment came from a wide variety of sources including the Big Lottery Fund, the Co-op Foundation, ViRSA grants, local councils and regional development agencies, rural community councils, Community First NEXUS grants, Communities Scotland, Highland and Islands Enterprise and other retailers such as Tesco and Sainsbury. More recently the Plunkett Foundation has helped CREs gain access to funds under the Village Core and Village SOS schemes.

Smaller grant schemes supported the purchase of a range of equipment, most commonly the purchase of new refrigeration equipment but help was also given to buy labelling machines, pricing guns, scales, A-frames and an EPOS system. Finally, almost one-fifth of the CRE surveyed also wished to retain or support the local Post Office branch and the provision of specialist training was a requirement in these cases.

Contacts with other large retailers such as Tesco or Sainsbury were normally about in-kind support (e.g. some management time or second-hand shelving) which was seen by the larger companies as part of their social mission. These links did not normally lead to the supply of products (although see the links to some co-operative societies reported under iv) below) or the establishment of links to other sources of finance or information. They were also often viewed with suspicion by the CREs, including those that accepted the help, because these are the same large retailers that make up much of their competition, and often any advice proffered focused too heavily on profitability rather than the community ethos.

\section{iii. 'Initial' trading phase}

Once a CRE is ready to open its shop it still has to make decisions on how to staff and manage it, after all many of local shops taken over closed because they were unprofitable. 
However, as shown in Figure 1, around, or even just below, the break-even line there is an area of relatively low profitability where the shop could still operate if manned wholly by volunteers (D). The organisational costs of volunteers are offset by limited opening hours, a limited product range or by the level of goodwill invested in the operation by members and shoppers. Indeed, the low level of operating costs may mean that a community shop can match or even beat a major supermarket on the price of some goods.

Many of the shops in the survey were still operating in this manner. The questionnaire data showed that there was a relationship between scale and the use of volunteers; the larger the CRE (in terms of turnover) the more it relied on a paid manager and paid staff. Similarly, the longer established CRE tended to rely more on paid staff; only $14 \%$ of the CRE established before 1990 were still volunteer-only, compared to $37 \%$ of those set up after the start of 2005 . Or to put it a slightly different way, in the CRE established before $198085 \%$ of the staff were on the payroll (either full-time or part-time); this fell to 35\% in the CRE established during the 1980 s, to $22 \%$ in the 1990 s and to just $10 \%$ in the CRE established since 2000.

Thus, most of the CRE relied on volunteer labour and a significant number were run wholly by volunteers. Volunteer-run shops provide significant cost savings over privately-run or managed shops which can help to counter-balance the necessarily higher costs of purchasing smaller quantities of goods. It should be noted that many of the participants when interviewed also stressed that they were involved either to meet their own individual social needs or those of the community. In terms of the former, the most common reasons provided were socialising ('to get out of the house') or to have something to do, because the children were either at school or had left home. For the latter, the most common reason given was a strong community purpose in retaining a shop or Post Office in the village, either as an end in itself (making a contribution to the community) or as a means of protecting the more vulnerable members of that community, such as the elderly or those without access to a car. 
Volunteer labour seemed to be most important when the CRE was new or if it faced high levels of competition from other retailers. (Despite their relative isolation, nearly all of the

CREs in the survey reported that they were now competing against the home delivery options on offer from at least one of the major supermarket operators.) As a CRE becomes established there is pressure for its operations to become more professional, to ensure that they meet the required legal standards, and a recognition that store operating standards have to be maintained. The needs of CREs in this phase have been met, in part, by the creation of support groups for the sharing of 'best practice' and the resolution of common problems. In Scotland these have been operating since 2001 under the auspices of the Community Retailing Network; in England they were organised initially by some of the Rural Community Councils, particularly those in Oxfordshire and Norfolk, and latterly by the Plunkett Community Shop Network.

There are also other costs associated with unpaid volunteers that may push the community towards employing a shop manager. These include the need to organise a staffing rota, a higher level of unplanned or irregular absences from the shop (younger volunteers may have training or job interviews to attend; retired volunteers may take more holidays or experience higher levels of sickness), less understanding of the method of operation of the shop, or even different views of the underlying mission of the shop or the CRE.

Anecdotal evidence from the shop visits, and CRE websites where available, suggests that many of the CREs have engaged their local communities in a common purpose and that this has spilled over into other activities. But it was also suggested in some cases that the retail strategy and the activities undertaken by management committees were not being driven by the community but by the views of the committee members alone. This was most evident in those CREs that had very small management committees or those which had not held meetings of the CRE membership in more than two years. 
In part, this might reflect 'volunteering fatigue' amongst the local community; it was also noted by some respondents that it was difficult to retain a common sense of purpose over a longer period of time. After the initial burst of enthusiasm that had led to the establishment of the CRE had faded away, many in the community had begun to treat the shop as if it were privately-run and to 'forget' that it was community-owned. As such, they began to judge it on the same terms as any other retailer, over-emphasising the higher prices of the goods sold compared to the social value of having the goods sold locally.

\section{iv. An established operation}

If the shop is successful these costs will begin to grow again however as extra goods and services are added or volunteers begin to experience some level of 'burn-out' from the higher than expected levels of involvement in the CRE. We can suggest that by point $\mathrm{E}$ the volunteers are likely to be supplemented by a part-time paid manager who will take on many of the more onerous duties and responsibilities. Whilst some CRE enterprises may begin with a paid manager this is often because the costs are funded by other bodies, such as a Development Agency or where it is needed to cope with the demands of a Post Office branch. If such outside support is not available, then employing full-time staff requires not just a relatively high level of turnover and profit but also a high degree of confidence in the enterprise precisely because of its immediate impact on costs.

A successful shop is likely to have strong links between the shop and the community. It is also likely to have built up a 'family' identity among the volunteer staff where they can trade time and other obligations in order to make the enterprise work. There is a strong element of social cohesion and of an 'us and them' attitude in this situation which produces the energy needed to get the shop up and running. 
Unfortunately, the introduction of a paid manager or of paid staff can weaken these strong links because it suggests that paid and volunteer staff may well have different motivations and different criteria for success ( $c f$ the role of volunteers in charity shops (Broadbridge and Horne 1994)), as well as weakening the link between the shop and the community. Ironically, therefore, the very mechanisms that can reflect a stronger position for the shop itself may also signal problems within the structure of the CRE.

There were some benefits to be gained from the larger scale of operations however. The first of these involved the opportunity to expand not just the range of goods on sales but also the range of services. For example, responding to the limited number of pharmacies in local communities some shops pick up prescriptions for customers whilst others have a similar service for dry cleaning and even allow parcels to be dropped-off. The local relationship is carried forward with the sale of tickets to local events and the provision of community information, as well as tourist information. In some cases beliefs in local food and sustainability are reflected in the provision of vegetable box delivery schemes.

Second, as a CRE becomes more professional in its operations it is better able to use the support provided by other retailers, which was mainly provided by established consumer cooperatives, including the Co-operative Group, Midcounties Co-op and Penrith Co-op. A number of the Scottish community co-operatives were working with the manager of a 'buddy' store of the Co-operative Group who provided advice within a longer-term relationship. And the largest of the community retail enterprises also benefitted from direct deliveries from the Co-operative Retail Trading Group, which is the central buying group for co-operative retail societies in the United Kingdom; however this required the shop to buy in larger quantities and to adhere to strict trading guidelines. 


\section{v. Long-term success}

If profitability climbs even further then the enterprise might reach point $\mathrm{F}$ where it retains both a paid manager and paid full-time or part-time staff, as in some of the Scottish community co-operatives (Calderwood and Davies, 2006). However, this brings a different set of organisational costs because of the potential separation of the membership from the running of the CRE and disengagement from its original purpose (Cox, 1994).

In particular, volunteers were either absent or more weakly connected to the running of the shop, but the shop was likely to be more closely linked to its suppliers and other sponsors. It would be operating more like a conventional retailer, at the cost of weaker ties to the local community and customers. For example, in the case of one shop that had been established only five years earlier, a member of the board responded that members had begun to forget that they owned the shop and instead they viewed the manager and paid staff of the shop as 'them', as opposed to the 'us' of the community.

\section{vi. Success or failure?}

It is also possible that having rescued the original shop and shown how it can be made profitable that the CRE will choose to return the shop to the privately-run sector (A) by selling it on to its management or another individual. This too should be seen as a successful outcome so long as the new private enterprise is sustainable in the long-run.

Finally, poor management or a change in the local retail environment might mean that the CRE falters. If there is no real continuing connection to the local community then it may fail altogether. On the other hand, the will to retain the shop may be high and the CRE may have to revert to volunteer-only operations in order to trim its costs (D). The Plunkett Foundation reported that a number of the community shops that they monitor had gone back to using volunteers, normally because they had lost their initial levels of community engagement. But 
in some cases this change, and the need to re-engage with the community, seemed to have reinvigorated the CRE. Volunteering made the links between the local residents and the community shop visible to all again.

Conceptualising the 'journey' in this way moves us away from thinking about the community shops purely in terms of their size or product offer and into questions around what the membership or community expects from the enterprise and what resources they can bring to bear on the problem. It is also recognised that whilst Figure 1 sees each phase as a stage towards a more settled, self-sustaining operation, there is no reason for every CRE to follow such a path. Some CREs may remain at point D where the community or social capital aspects dominate the operation but with the danger that it leads to a gradual decline in enthusiasm for the business. Other CREs may aim immediately for point $\mathrm{F}$, where the economic aspect dominates and the shop is self-sustaining, but with the danger that it becomes increasingly divorced from the needs of its membership.

\section{Discussion}

This paper has been based on the results of a survey of CREs and the community shops that they run. It shows that most of these shops really do meet a local need and that they tap into and even expand a feeling of local community, providing a focus and meeting place that might not have existed previously. In this way, it may be that the shops show the benefits of localism. Strong links between the enterprise and the community can be established in a variety of ways and these can contribute positively to the success of the shop and to a stronger sense of local community. Respondents talked about the skills and connections that local residents had brought to the enterprise and the ways in which these connections had strengthened the development and operation of the shop. 
However, this dependence on the involvement of local people in the setting up and running of the local shop can be more problematic than might appear initially. As has been shown above, it has seldom been sufficient for a local community to desire or understand the need for a local community shop. Each stage in the establishment of a CRE and shop, from planning through to keeping the shop running for many years, has generally required support from outside agencies. Failure rates are reported to be much higher in those cases where no support is sought beforehand. And the local community is not a static concept; the people change and their attitudes to the shop and shopping also change over time, so that a CRE that was successful in 2000 will need to reinvent itself to stay in contact with the community.

The paper also explored the presence of potential barriers to the establishment and survival of these enterprises. Localism provides an important opportunity to ensure that communities retain those services that they feel are important for their health and vitality. However, this research also shows that most CREs benefit from specific support from local and national organisations at different stages in their development. In this way, it can be seen that they reflect local identity (a position that pre-dates any efforts towards localism from government) and they may be subject to less central interference (or given more support) than previously, although this tends to relate primarily to the start-up phase. But they are most certainly not free to effect too wide a range of particular outcomes. In part, this relates to the continued presence of a range of controls on their activities, including health and safety and employment issues. But more importantly it relates to the need for outside advice and financial aid from a variety of sources if they are to open and then grow the business. As the influence of local government or the Regional Community Councils has waned, so the influence of bodies such as the Plunkett Foundation has grown. 
CRE are also still subject to the constraints placed upon them by the wider business environment and the manner in which that develops and is controlled by government. The retail sector is a dynamic one and the continued expansion of large firms into rural markets (either through new stores, home delivery or the internet) affects the operation and viability of even the most remote community shops. Changes to the way the Post Office network is run and funded also affect the viability of some CRE. And, finally, even a successful CRE will find it difficult to meet the requirements of modern supply chains. This suggests that future research is needed to consider the forms of support that have worked in the past and how they can be applied more widely - at a time when central and local government are withdrawing from this area.

There is evidence of a path which requires the use of volunteer-only labour as the only means by which the shops can survive initially. Beyond the initial start-up phase, if the link to the local community is not strong enough then the shop may not develop successfully and it may close or never establish its own identity. In the medium-term, development into a local shop that can support a paid manager or paid staff often requires links to outside bodies that can provide cost-effective training and supply chain functions. Finally, the more professional the shop becomes (or appears to become) the more it is likely to be seen as separate and no longer owned by the local community that created it. This gap can introduce governance issues and the likelihood that the shop will either be returned to the private sector or even close.

\section{Conclusions}

Overall, therefore, the picture is of local communities wishing to respond to the loss of retail facilities by setting up their own shop. Often this will not just replicate previous provision but will try to offer something different such as local produce or local services in order to compete with larger retailers. But enthusiasm and even money are generally not enough on 
their own; community shops require CRE with good governance structures and a clear idea of their long-term purpose. The evidence suggests that they require finance and advice not just for their establishment but also at different stages in their development as they seek to cope with changes in their communities and in the retail sector. The paper reveals a key limitation of localism within the retail sector by demonstrating the conflict between the desired objective of local autonomy and the influence of external competitive and consumer forces upon the options available to these shops. Successful localism still requires a framework that nurtures and supports local communities as they try to understand how to create a shop that will be a sustainable community resource.

\section{Funding}

The original survey work undertaken for this research was supported by the Co-operative Group.

\section{References}

Broadbridge, A. and Horne, S. (1994) Who Volunteers for Charity Retailing and Why, The Service Industries Journal, 14(4), pp. 421-437.

Calderwood, E. and Davies, K. (2006) The impact of community co-operatives on shopping behaviour in rural communities in Scotland, Review of International Co-operation, 99(1), pp. 53-62.

Calderwood, E. and Davies, K. (2012) The Trading Profiles of Community Retail Enterprises, International Journal of Retail and Distribution Management, 40(8), pp. 592-606.

Cotterill, R.W. (1982)(ed) Consumer Food Cooperatives (Danville IL: Interstate Publishers). 
Cox, C. (1994) Storefront Revolution. Food Co-ops and the Counterculture (New Brunswick NJ: Rutgers University Press).

Department for Communities and Local Government (DCLG) (2011) A Plain English Guide to the Localism Bill (London: DCLG).

Department for Environment, Food and Rural Affairs (DEFRA) (2006) Sustainable Models of Community Retailing. Final Report (London: DEFRA).

Fulton, M. and Hammond Ketilson, L. (1992) The Role of Cooperatives in Communities: Examples from Saskatchewan, Journal of Agricultural Cooperation, 7(2), pp. 15-42.

Grott, R. (1987) Why Co-ops Die: An Historical Analysis, Cooperative Grocer, No. 9 , February-March.

Hall, S.M. (2011) High street adaptations: ethnicity, independent retail practices, and Localism in London's urban margins, Environment and Planning A, 43, pp. 2571-2588.

McEntee, J. (2010) Contemporary and traditional localism: a conceptualisation of rural local food, Local Environment: The International Journal of Justice and Sustainability, 15(9-10), pp. $785-803$.

Perry, M. and Alcock, J. (2010) Community Owned Village Shops - A Better Form of Business, Journal of Co-operative Studies, 43(2), pp. 37-45.

Pratchett, L. (2004) Local Autonomy, Local Democracy and the 'New Localism, Political Studies, 52, pp. 358-375.

Schoenborn, A. (2011) The Right to Retail. Can localism save Britain's small retailers? (London: ResPublica). 
Smith, A. and Sparks, L. (2000) The role and function of the independent small shop: the situation in Scotland, The International Review of Retail, Distribution and Consumer Research, 10 (2), pp. 205-226.

Thomas, A. and Cornforth, C. (1989) The Survival and Growth of Worker Co-operatives: A Comparison with Small Businesses, International Small Business Journal, 8(1), pp. 34-50.

Welford, R. (1990) The Co-operative as a Fringe Firm and the Notion of Self-Exploitation, International Small Business Journal, 8(3), pp. 39-48. 
Figure 1: Threshold levels for privately-run and community-owned enterprises

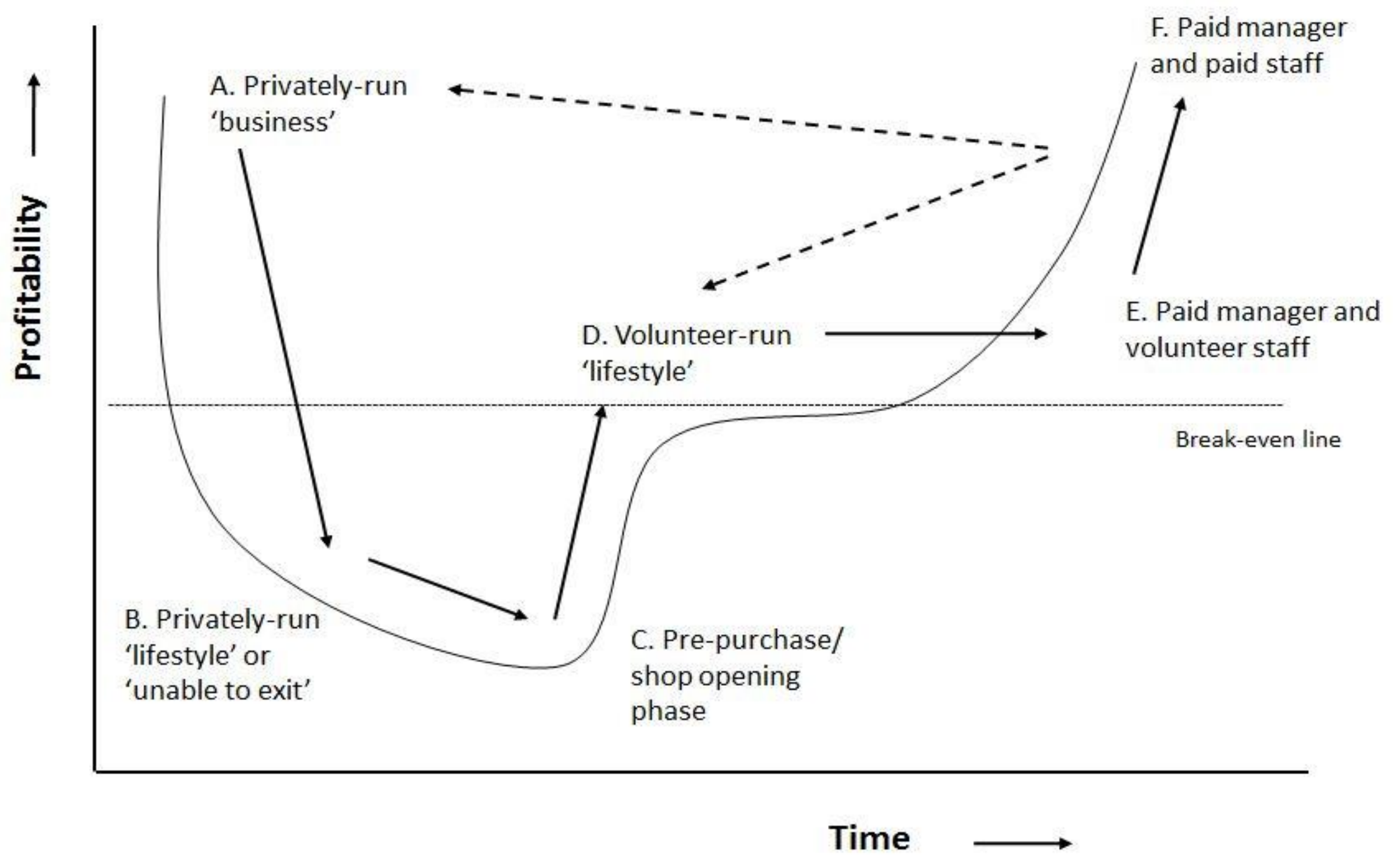

